\title{
IMPLEMENTASI CHATBOT "ALITTA" ASISTEN VIRTUAL DARI BALITTAS SEBAGAI PUSAT INFORMASI DI BALITTAS
}

\author{
Eka Yuniar ${ }^{1)}$ dan Heri Purnomo ${ }^{2)}$ \\ 1,2) STMIK PPKIA Pradnya Paramita \\ ${ }^{3)}$ Departemen Sistem Informasi \\ e-mail: eka@stimata.ac.id ${ }^{1)} \underline{\text { heri @ stimata.ac.id }}^{2}$
}

\begin{abstract}
Conversational Bot atau Chatbot adalah sebuah konten yang divisualisasikan dalam format obrolan dan pengguna dapat berinteraksi dengan sistem menggunakan teks. Teknologi cerdas ini merupakan salah satu perkembangan dari Revolusi Industri 4.0 yang harus diimplementasikan guna meningkatkan pelayanan pada information service di segala industri terutama di BALITTAS (Balai Penelitian Tanaman Pemanis dan Serat) yang dinamakan ALITTA. ALITTA diimplementasi dengan tujuan untuk membantu pelayanan informasi dengan mesin penjawab otomatis, yang dapat melayani satu per satu pertanyaan yang dikeluhkan oleh pelanggan maupun pencari informasi BALITTAS secara cepat dan tidak terkendala waktu seperti jam kerja kantor, maupun terkendala dengan jumlah tenaga kerja. Chatbot ini dibangun dengan menerapkan sistem pakar dengan menggunakan metode forward chaining. Metode forward chaining digunakan untuk mencari kesimpulan dari fakta-fakta yang terkumpul. Metode forward chaining yang digunakan dalam sistem ALITTA menyelesaikan proses pencarian jawaban berdasarkan kata kunci dari pertanyaan user, dengaan cara mencari kata kunci yang digunakan sebagai jawaban atas respon pertanyaan user yang telah didaftarkan sebagai intents. Hasil penelitian ini adalah terciptanya chatbot "ALITTA" sebagai asisten virtual dari BALITTAS yang dapat membantu masyarakat dalam mencari informasi secara flexibel dan tidak terikat waktu yang berkaitan dengan tanaman, hama, dan kegiatan-kegiatan lainnya yang terdapat di BALITTAS.
\end{abstract}

Kata Kunci : ChatBot, Balittas, forward chaining, kecerdasan buatan, asisten virtual

\section{PENDAHULUAN}

$\mathrm{B}$ (Balai Penelitian Tanaman Pemanis dan Serat) Malang adalah Balai yang melakukan beberapa kegiatan penelitian (genetika, morfologi, fisiologi, ekologi, entomologi, dan pitofatologi), pembenihan dan menghasilkan teknologi yang berkaitan dengan tanaman tembakau, pemanis, serat, dan minyak industri. Selain kegiatan tersebut, Balitas juga melakukan kegiatan kerjasama, informasi, dan rekomendasi, serta penyebarluasan dan pendayagunaan hasil - hasil penelitian tanaman tembakau, pemanis, serat, dan minyak industri. Memberikan saran kebijakan dalam agribisnis tanaman tembakau, pemanis, serat, dan minyak industri juga merupakan salah satu kegiatan yang telah banyak dilakukan oleh Balittas. [1]

BALITTAS telah memanfaatkan perkembangan teknologi di bidang informasi untuk meningkatkan kualitas pelayanan mereka. Dalam melaksanakan proses pelayanan, BALITTAS ini telah menggunakan media informasi website dan juga sosial media seperti Facebook, Instagram, dan Twitter yang tak luput sebagai salah satu media informasi andalan.

Animo masyarakat terhadap pelayanan dari Balitas sendiri sangat besar, terbukti dari total layanan perhari dalam website BALITTAS mencapai +1473 pengunjung website/hari, dengan total kunjungan perbulan dapat mencapai 881.964 pengunjung/bulan update data diambil tgl 9 April 2019 pukul 14.45 WIB. Pembuatan chatbot dibutuhkan sebagai salah satu sarana tambahan untuk konsultasi pelayanan yang sifatnya berulang-ulang. Hal ini dapat menimbulkan permasalahan terhadap tracking pelayanan (sejauh 
mana layanan pertanyaan user) semakin banyak. Dan seluruh pegawai juga memiliki jam kerja serta kesibukan lainnya, sehingga pemberian informasi menjadi terlambat.

Untuk mengatasi permasalahan yang telah dijelaskan di atas, maka peneliti membuat sebuah Chatbot. Chatbot sendiri adalah Robot Chat berbasis layanan yang didukung oleh sekumpulan aturan dan terkadang kecerdasan buatan, yang berinteraksi dengan pengguna melalui antarmuka obrolan. Chatbot ini dapat menjawab pertanyaan yang ditanyakan user selama 24 jam dan tidak terikat waktu. Konten ini dinamakan sebagai "ALITTA" Asisten Virtual dari BALITTAS sebagai Pusat Informasi di Balai Penelitian Tanaman Pemanis dan Serat di BALITTAS dirasa diperlukan sebagai salah satu pelayanan terhadap para penelit baik dari internal maupun eksternal BALITTAS.

ALITTA dibuat dengan mengintegrasikan salah satu layanan sosial media yaitu telegram dengan memanfaatkan teknologi API (Application Programming Interface). Sistem kerja ALITTA adalah dengan memecah susunan kalimat menjadi kata yang kemudian oleh sistem akan dicari kata kunci sebagai jawaban atas respon pertanyaan user. Metode yang digunakan dari sistem ini yaitu forward chaining. Pada penelitian ini penulis ingin memanfaatkan platform pesan singkat tersebut yang akan digunakan sebagai portal untuk pelanggan berinteraksi dengan sistem pengelolaan informasi.

Permasalahan yang diteliti adalah sebuah aplikasi layanan conversational berbasis robot chat yang dapat memudahkan petugas untuk interaksi 2 arah. Selain itu, dilakukan kegiatan merancang dan mengimplementasikan conversational flow untuk kebutuhan chatbot dalam menangani pertanyaan user.

Tujuan dari penelitian ini adalah untuk membuat sebuah aplikasi layanan conversational berbasis robot chat yang dapat memudahkan petugas untuk interaksi 2 arah. Selain itu chatbot digunakan sebagai sarana penyampaian informasi tentang BALITTAS yang ditujukan kepada pengguna yang menginginkan tentang informasi tanaman, hama, dan kegiatan lainnya di BALITTAS.

\section{TINJAUAN PUSTAKA}

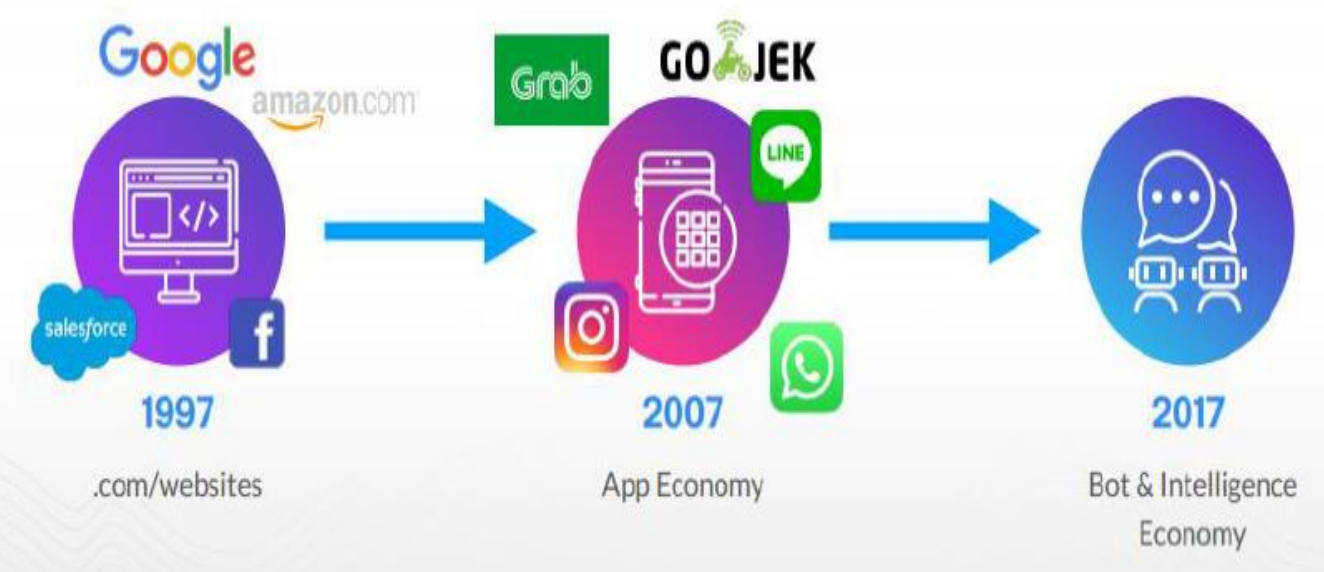

Gambar 1. Perkembangan Teknologi Masyarakat/Konsumen

Perkembangan teknologi menuntut pelaku usaha baik dibidang bisnis maupun government untuk dapat mengikuti perkembangan. Dapat dilihat dalam Gambar 1, pada tahun 1997 sejak muncul website perkembangan teknologi berbasis website. Sedangkan pada tahun 2007 perkembangan aplikasi mobile mulai mewarnai dunia teknologi. Dan pada era sekarang dimulai pada tahun 2017 penggunaan Bot dan Intelegence system dibutuhkan oleh masyarakat. 


\section{ChatBot}

Chatbot merupakan pengembangan aplikasi komputer yang dirancang untuk dapat berinteraksi dengan manusia melalui pesan teks, maupun suara. Chatbot telah dibekali dengan kecerdasan buatan dan pemrosesan bahasa alami/ NLP yang membuatnya menjadi aplikasi komputer yang cerdas dan dapat menjawab pertanyaan yang diberikan oleh manusia. Chatbot dibangun untuk membantu manusia dalam hal pelayanan informasi/ customer service, dengan topik yang sudah. Banyak chatbot yang sudah ada dibangun sesuai dengan topik dan permasalahan yang ingin dipecahkan oleh seseorang untuk keperluan pribadi ataupun keperluan bisnis lainnya. Di dalam chatbot tersebut telah ditanamkan model pengetahuan untuk menjawab pertanyaan-pertanyaan yang sesuai dengan konteks yang telah disusun. Chatbot terdiri dari tiga kombinasi, di mana ketiga kombinasi inilah yang membentuk sebuah chatbot [2], di antaranya adalah:

\section{a) User Interface}

User interface merupakan tampilan antar muka dalam chatbot yang merupakan jembatan antara chatbot dan user saling berinteraksi. User Interface haruslah dapat memberikan pengalaman yang lebih baik kepada user ketika berinteraksi dengan Chatbot. Melalui aplikasi pesan berbasis text.

b) Artificial Intelligence

AI atau Artificial Intelligence akan membuat aplikasi paham dalam setiap interaksi yang terjadi dengan user, karena chatbot merupakan salah satu pengembangan aplikasi sistem cerdas antara manusia dengan komputer.

c) Integrasi

Integrasi dengan sistem lainnya akan menambah kekayaan fitur yang terdapat di dalam suatu chatbot. Dengan mengintegrasikan chatbot ke sistem yang lain dapat menyediakan informasi tambahan. Dengan cara ini chatbot mampu memberikan informasi yang lebih kaya kepada user, seperti pada penelitian kali ini yang akan mengimplementasikan chatbot pada salah satu sosial media yaitu telegram.

Di keperluan bisnis chatbot dapat membantu pada pemecahan permasalahan yang berkaitan dengan komunikasi dengan pelanggan untuk meningkatkan pelayanan dan pengalaman dalam hal berkomunikasi, chatbot sangat lah efektif digunakan dalam permasalahan yang fokus dan spesifik serta dapat diprediksi. Pada perkembangan dunia bisnis yang sangat cepat, chatbot menjadi salah satu alternatif solusi, ini akan memudahkan pelanggan menjangkau dan melakukan interaksi dengan bisnis.

\section{Platform API.AI}

API.AI adalah sebuah platform yang menyediakan layanan NLP (Natural Language Processing) dan NLU (Natural Language Understanding). Layanan ini digunakan untuk membuat chatbot lebih cerdas dan dapat memahami maksud dari apa yang ditanyakan oleh user. Natural language Processing adalah salah satu disiplin ilmu dari Artificial Intelligence yang fokus terhadap interaksi manusia dan komputer melalui bahasa alami yang manusia gunakan. Dalam NLP tujuan yang ingin dicapai adalah kemampuan sebuah sistem NLP memiliki pengetahuan bahasa alami baik dari susunan kalimat, arti dari kata tersebut dan maksud dari sebuah kalimat. Sedangkan NLU sendiri adalah merupakan sub bidang dari NLP, di mana fokus tujuan dari NLU itu sendiri adalah untuk melakukan pemahaman terhadap suatu kalimat dan melakukan analisis semantik. API.AI ini sendiri tidak mendukung domain pengetahuan bahasa Indonesia namun memiliki banyak sekali domain pengetahuan dalam bahasa inggris. Domain adalah koleksi pengetahuan dan struktur data. Di dalam API.AI sendiri telah banyak basis pengetahuan yang sudah tertanam di sistem layanan API.AI ini. Koleksi pengetahuan yang terdapat pada layanan ini di antaranya adalah entitas musisi, bandara, dll. Namun tiadanya dukungan bahasa indonesia di dalam layanan ini bukan berarti layanan ini tidak dapat digunakan oleh peneliti yang notabene berbahasa indonesia. 


\section{Bot Telegram}

Telegram merupakan salah satu social media yang banyak diinstall orang. Telegram menyediakan sebuah fitur API (Application Programming Interface) yang memungkinkan adanya fitur bot. Fitur Bot digunakan untuk melakukan dirrect chatting dengan menggunakan robot chat yang memungkinkan pengguna untuk melakukan pembuatan chatbot sesuai dengan keinginan user. Fitur bot dalam telegram dimulai dengan melakukan pendaftaran terhadap akun bot yang digunakan sebagai chatbot. Pendaftaran akun bot tersebut dilakukan di @BotFather yang telah diberikan oleh penyedia layanan telegram.

\section{Forward Chaining}

Forward Chaining adalah metode pencarian atau pelacakan yang dimulai dengan informasi yang ada penggabungan rule untuk menghasilkan suatu kesimpulan atau tujuan. Forward chaining secara umum menghasilkan suatu goal, dan merupakan suatu metode inferensi yang melakukan penalaran dari suatu masalah kepada solusinya.[5]

\section{METODE PENELITIAN}

Penelitian yang akan dilakukan merupakan studi kasus tentang kajian implementasi ALITTA sebagai asisten virtual dari BALITTAS yang dapat membantu masyarakat dalam mencari informasi yang berkaitan dengan tanaman, hama, dan kegiatan-kegiatan lainnya yang terdapat di BALITTAS yang berguna peneliti dan pencari informasi baik internal maupun eksternal. Tahapan rancangan penelitian yang akan dilakukan :

1. Identifikasi dan Analisis kebutuhan desain

Identifikasi masalah dilakukan dengan caara menggali informasi secara terperinci dan melakukan penguraian terhadap data serta komponen yang dibutuhkan untuk sistem yang akan dibangun, sehingga sistem yang dibangun diharapkan telah sesuai dengan harapan dan keinginan pengguna. Proses analisis ini penulis laksanakan dengan melakukan observasi dan wawancara langsung ke petugas Balai untuk menggali informasi yang di butuhkan.

Pembuatan chatbot dilakukan untuk memberikan pelayanan informasi yang berkaitan dengan kegiatankegiatan yang terdapai pada Balittas antara lain, kegiatan kerjasama, pusat informasi, rekomendasi, serta pendayagunaan hasil-hasil penelitian yang telah dilakukan oleh pihak Balai.

2. Mendeskripsikan desain arsitektur ALITTA

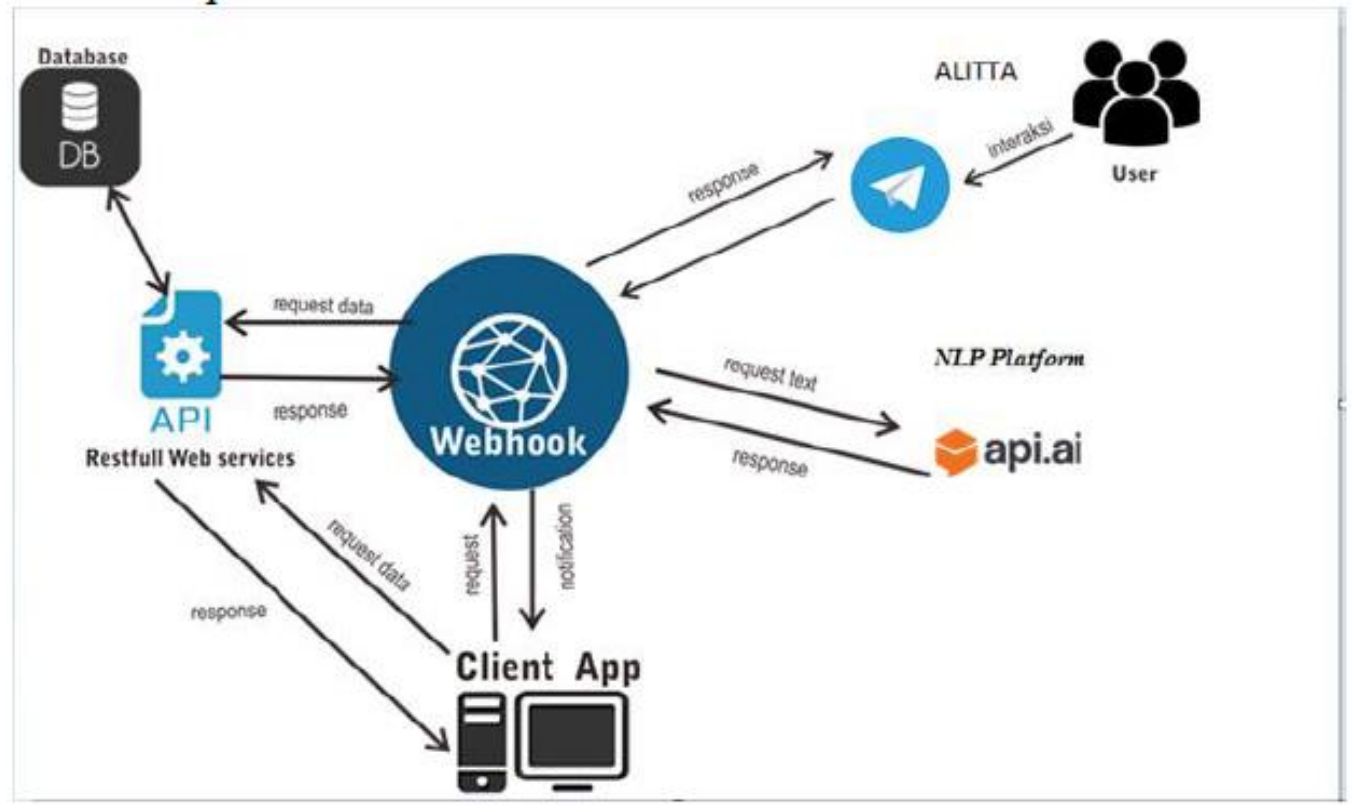

Gambar 2 Rancangan Arsitektur Chatbot ALITTA 
Gambar 2 di atas merupakan rancangan Rancangan Arsitektur Chatbot ALITTA yang terintegrasi dengan beberapa komponen lainnya seperti layanan pesan Telegram dan layanan NLP yaitu API.AI. Terdapat komponen-komponen yang berada di dalam rancangan arsitektur tersebut di antaranya adalah restfull api web services, database, webhook, Messenger, layanan API.AI, dan aplikasi di sisi user. Untuk komponen di dalam chatbot sendiri terdapat komponen dari platform atau layanan yang digunakan yaitu layanan Telegram dan API.AI. Database merupakan tempat di mana data-data disimpan, dan diolah. Database akan di hosting dan dapat diakses secara online. Untuk dapat mengelola data yang terdapat di dalam database maka dibutuhkan sebuah antarmuka yang dapat melakukan tugas-tugas pengelolaan data yang ada di dalam database. Restfull API web service merupakan layanan yang berbasis REST.

REST (Representational State Transfer) adalah standar komunikasi yang sering diterapkan dengan berbasis web, REST menggunakan HTTP (Hypertext Transfer Protocol) untuk protocol komunikasi data. Pembuatan web services berbasis REST ini bertujuan agar data yang terdapat di dalam database dapat dilakukan pengolahan dengan mengakses layanan dari platform apapun.

Webhook merupakan HTTP callback. Konsep dari webhook sederhana, webhook akan bekerja apabila terdapat suatu kejadian yang datang dari luar. Dalam hal ini adalah HTTP pos yang merupakan request yang diterima. Kelebihan dari penggunaan webhook untuk pengembangan aplikasi adalah dalam hal integrasi antara satu aplikasi satu dengan yang lainnya.

Fungsi utama dari webhook itu sendiri adalah menerima data secara realtime dan mengirimkannya kembali. Dalam rancangan arsitektur tersebut dapat jelas dilihat bahwa webhook lah yang menjembatani antara chatbot dan sistem pengelolaan pesanan. Dengan menggunakan platform pesan teks Telegram pelanggan melakukan interaksi dengan sistem, kemudian request text dari pelanggan tersebut akan selanjutnya diolah di platform NLP API.AI. Melalui webhook, antara Telegram dan API.AI akan saling berinteraksi. Request yang berupa teks tersebut diolah di API.AI untuk dicari tahu dan diidentifikasi maksud dari request tersebut. Apabila misalnya request text tersebut merupakan pertanyaan untuk melakukan pengecekan order maka API.AI akan memberi identifikasi bahwa maksud dari request tersebut adalah pengecekan order. Layanan API tersebut akan mengirimkannya kembali ke webhook untuk diolah lebih lanjut. Webhook juga akan berkomunikasi dengan resftull web services untuk mendapatkan data yang dibutuhkan.

\section{Identifikasi Knowledge base ALITTA}

Pembuatan chatbot dilakukan dengan melakukan identifikasi knowledge base yang akan di inputkan ke dalam sistem AI. Knowledge base adalah basis pengetahuan berisi pengetahuan-pengetahuan dalam penyelesaian masalah. Basis pengetahuan ini juga berisi tentang aturan-aturan yang berkaitan dengan pengetahuan tersebut. Dalam proses ini pengetahuan direpresentasikan menjadi basis pengetahuan dan basis aturan selanjutnya dikodekan, dikumpulkan, dan dibentuk secara sistematis.[4] Mekanisme identifikasi knowledge base tentang konsultasi layanan Jasa meliputi sebagai berikut :

a. Konsultasi Layanan Data Tanaman Varietas Unggul

Konsultasi layanan meliputi konsultasi penyediaan data tanaman di Balittas meliputi tanaman Tanaman Tembakau dan Tanaman Serat yang memiliki varietas unggul.

b. Konsultasi Layanan Penyediaan Benih

Konsultasi layanan meliputi konsultasi mekanisme permintaan penyediaan Benih dari Tanaman Tembakau dan Tanaman Serat yang terdapat di Balittas.

c. Konsultasi Layanan Benih Sumber

Konsultasi layanan meliputi konsultasi mekanisme permintaan benih sumber dari Tanaman Tembakau dan Tanaman Serat yang terdapat di Balittas.

d. Konsultasi Magang

Konsultasi layanan meliputi konsultasi mekanisme Magang/ Pelatihan yang terdapat di Balittas. 


\section{Pembuatan Inference Engine ALITTA}

Mesin Inferensi merupakan alur sistem yang digunakan dalam sistem pakar untuk menghasilkan informasi baru dari knowledge base yang telah diketahui. Dalam sistem pakar proses inferensi dilakukan dalam suatu modul yang disebut dengan mesin inferensi (Inference Engine). Inference Engine yang digunakan dalam sistem ALITTA dibuat dalam platform API.AI. Fungsi Inferensi Engine adalah :

a. Memberikan pertanyaan kepada user.

b. Menambah jawaban pada block intents

c. Menambahkan fakta baru tersebut pada entities sebagai working memory.

d. Mencocokkan fakta pada working memory dengan rule.

Dengan menggunakan metode Forward Chaining pengujian aturan dilakukan satu persatu secara berurutan. Saat tiap aturan diuji, sistem akan mengevaluasi apakah kondisi benar atau salah. Dengan kata lain, penalaran dimulai dari fakta terlebih dahulu untuk menguji hipotesis. Forward chaining adalah data driven karena inferensi dimulai dengan informasi yang tersedia dan kemudian konklusi akan diperoleh. Pada sistem pakar umumnya metode penalaran atau mesin inferensi tersebut diimplementasikan dalam bentuk baris-baris coding dalam bahasa pemrograman tertentu. Maka sudah dapat diperkirakan bahwa sistem pakar dengan beberapa knowledge hanya dapat diisi beberapa kepakaran yang memiliki teknik inferensi yang sama dan memiliki struktur knowledge base yang sama.[4]

\section{A. PERANCANGAN SISTEM}

1. Activity Diagram Alitta

Pada Gambar 3 berikut ini merupakan Activity Diagram dari Bot Asisten Virtual dari Balittas (Alitta)

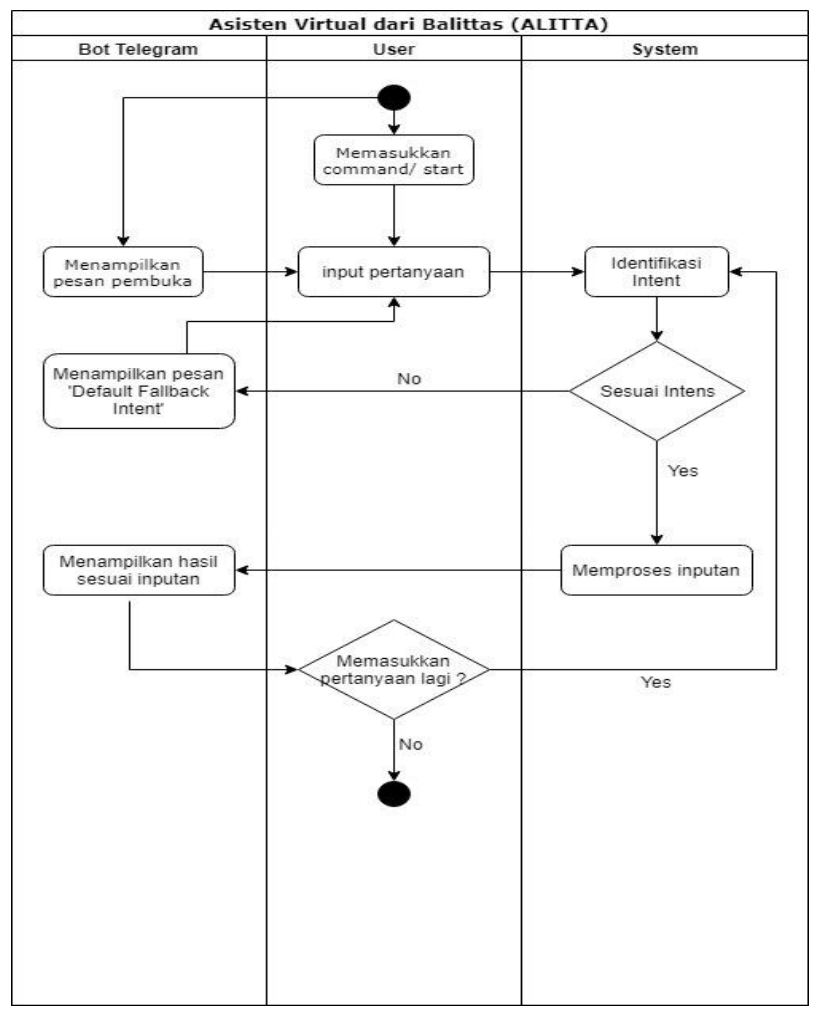

Gambar 3 Activity Diagram Chatbot ALITTA 
Setelah user/client menambahkan bot Alitta sebagai teman, pertama-tama user/client tersebut harus memulai percakapan dengan memasukkan command /start. Kemudian bot akan menampilkan pesan pembuka. Kemudian user akan melakukan input pertanyaan yang nanti akan diproses dalam sistem dan disebut dengan intent, apabila intent sesuai maka akan langsung diproses inputan sesuai dengan jawaban user, apabila tidak sesuai maka alitta bot akan menampilkan "default fallback intent" dengan chat kata-kata seperti "saya tidak mengerti maksud anda?", "mohon masukkan ulang pertanyaan anda", dll. Setelah ditampilkan hasil dari inputan tersebut, user bisa memasukkan pertanyaan kembali atau mengakhiri percakapan.

\section{Tabel NLP}

NLP atau Natural Language Processing adalah proses pembuatan model komputasi dari bahasa sehingga memungkinkan terjadinya interaksi antara manusia dan komputer dengan perantaraan bahasa alami yang dipakai manusia. NLP memodelkan pengetahuan terhadap bahasa, baik dari segi kata, bagaimana katakata bergabung menjadi suatu kalimat dan konteks kata dalam kalimat.[2]. Tabel NLP berisi tentang data kata-kata yang memungkinkan untuk ditanyakan oleh manusia. Sebagai contoh dalam Tabel 1 merupakan contoh dalam intent Magang.

\begin{tabular}{ll}
\multicolumn{2}{c}{ Tabel 1.Intent Magang } \\
\hline \hline Referensi Kata & Sinonim \\
Magang & Magang, magang kerja, pkl, \\
& praktek kerja lapangan, psg, \\
& ojt, kkn \\
\hline \hline
\end{tabular}

Dalam Tabel 1 Kata Magang memiliki banyak sinonim, sedangkan dari kata magang banyak sekali pertanyaan user yang berbeda-beda kata, apabila chatbot tidak dilengkapi dengan NLP maka harus melakukan deskripsi terhadap masing-masing kata tersebut. Sedangkan apabila sistem telah dilengkapi oleh NLP, berbagai macam sinonim dari kata magang akan dibuat sebagai key/ kata kunci dalam intent dan di deskripsikan dalam entitis phrases sebagai berikut :

Tabel 2. Entitis Phrases

\section{Jenis Pertanyaan User}

Apakah masih menerima mahasiswa magang di Balittas?

Apakah masih menerima pelajar PSG di Balittas?

Saya mau tanya informasi tentang PKL di Balittas?

\section{Tabel Respon}

Chatbot yang baik adalah sebuat sistem yang dapat melakukan pengembalian respon dari seluruh inputan user baik itu yang sesuai dengan kriteria maupun bukan. Tabel respon dalam Alitta terdiri dari 3 Jenis yaitu:

Tabel 3. Tabel Respon tentang Magang

\begin{tabular}{lll}
\hline \hline Jenis Activity & Contoh Pertanyaan & Respon \\
Opening Activity & Selamat Pagi & Hai selamat pagi, Selamat datang di ALITTA (Asisten \\
& & Virtual dari Balitas). Ada yang bisa kami bantu? \\
& Siang & Hai siang, Selamat datang di ALITTA (Asisten Virtual \\
& & dari Balitas). Ada yang bisa kami bantu? \\
Main Activity & Apa terdapat lowongan untuk & Baik, untuk informasi magang, silahkan mengirimkan \\
& Magang? & Surat Permohonan Magang atau bisa datang langsung \\
& d/a Balai Penelitian Tanaman Pemanis dan Serat........... \\
\hline
\end{tabular}


Saya mw tanya info tentang KKN di

Balittas?

Closing Activity

Terima kasih

Baik, untuk informasi magang, silahkan mengirimkan Surat Permohonan Magang atau bisa datang langsung d/a Balai Penelitian Tanaman Pemanis dan Serat

Baik, Terima kasih telah menggunakan Alitta. Semoga Informasi yang didapat bermanfaat.

\section{HASIL DAN PEMBAHASAN}

Pengujian sistem dilakukan dengan menggunakan metode Black Box sistem, yaitu pengujian yang dilakukan untuk melihat setiap fungsi berjalan dengan baik sesuai dengan kegunaannya. Untuk melakukan pengujian terlebih dahulu pengguna harus menggunakan aplikasi telegram.

Halaman awal dari user yang menggunakan telegram dengan invite akun Alitta di alamat http://t.me/Alitta_bot. Kemudian akan muncul akun dengan tombol command/ start seperti pada Gambar 4 berikut ini :

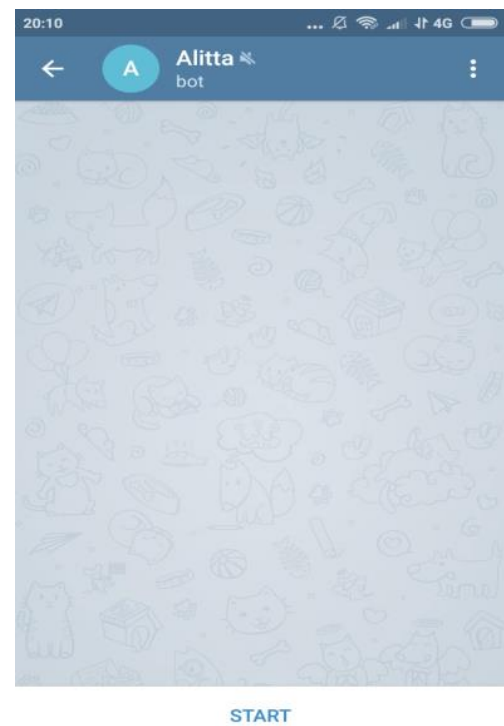

Gambar 4. Tampilan awal Alitta

User akan melakukan klik tombol /start untuk memulai percakapan dengan Alitta, akan terlihat seperti pada Gambar 5, berikut ini:

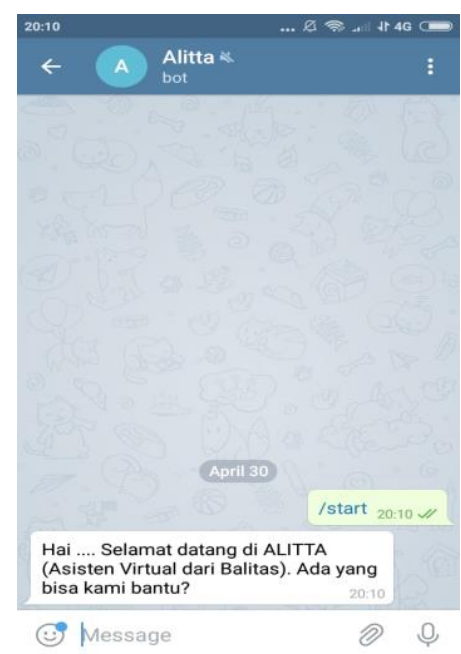

Gambar 5 Tampilan Pesan Pembuka Alitta 
ANTIVIRUS: Jurnal Ilmiah Teknik Informatika (p - ISSN: 1978 - 5232; e - ISSN: 2527 - 337X)

Vol. 12 No. 1 Mei 2019, pp. $24-35$

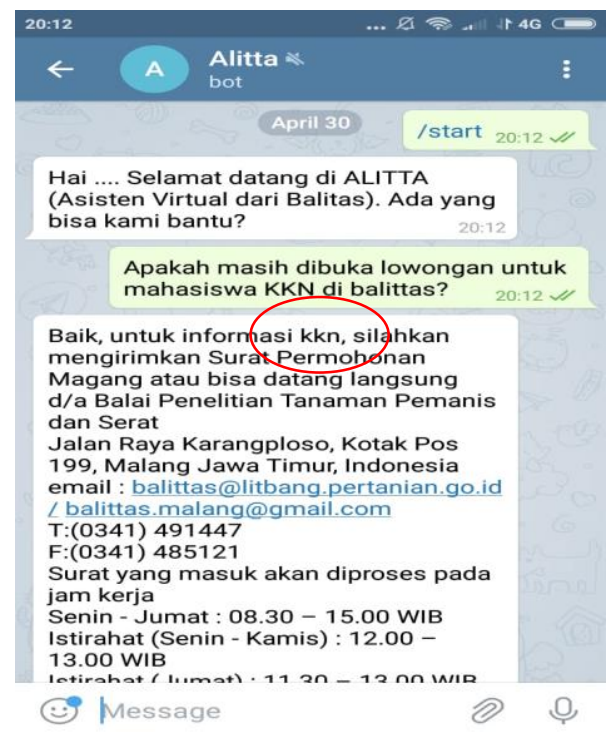

Gambar 6 Tampilan Input Pertanyaan \& Replay di ChatBot

Pada Gambar 6 user melakukan input pertanyaan perihal kegiatan KKN yang terdapat di Balittas. Kata KKN/ Magang/ PSG, dsb sesuai dalam Tabel 1 telah dideskripsikan sebagai sebuah intent, sehingga ketika user melakukan pertanyaan berkaitan dengan kata-kata tersebut maka feedback chat yang ditampilkan adalah sesuai dengan Gambar 6, dan kata KKN akan berubah bergantung dengan inputan user yang menginputkan pertanyaan.

Pada Gambar 7 dapat melakukan setting input intent yang digunakan untuk melakukan replay dari conversation yang dilakukan sebagai berikut :

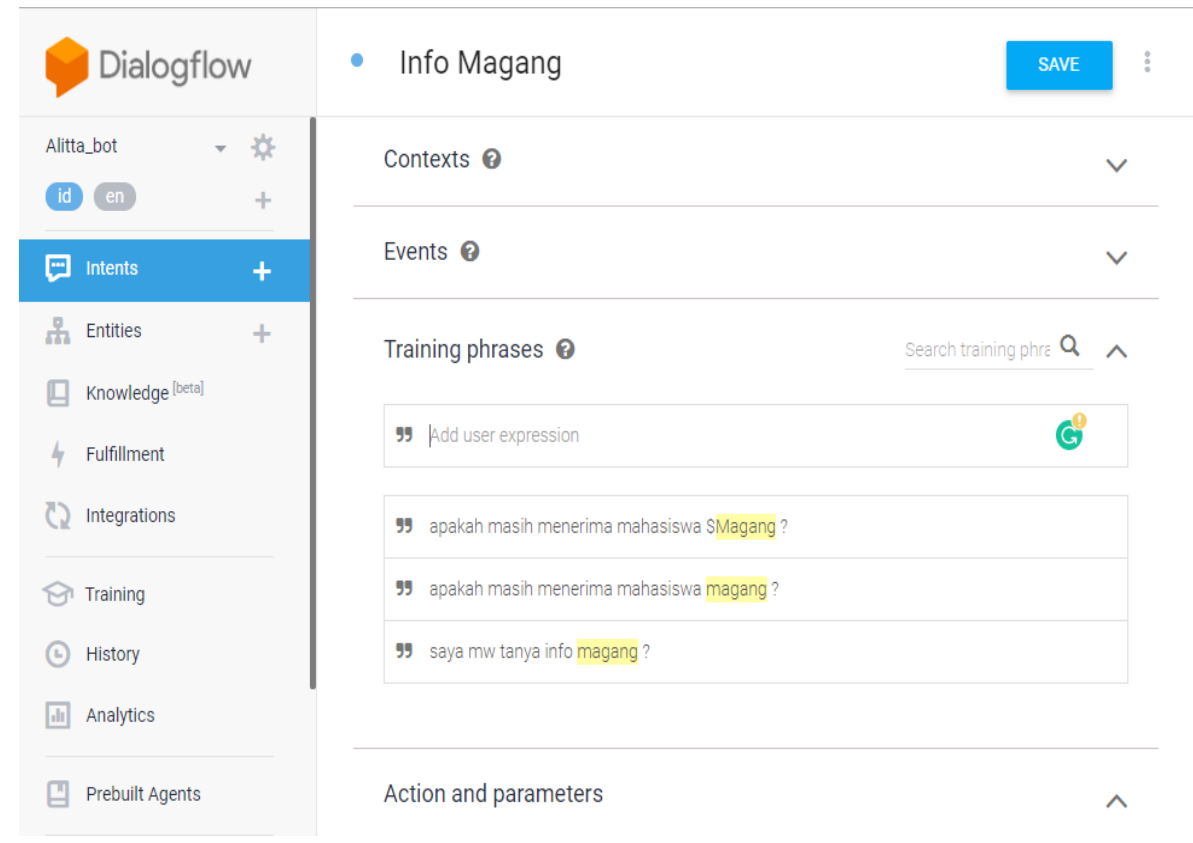

\section{Gambar 7 Tampilan Setting Intent}

Pengaturan Intent berisi tentang context, event, phrases dan action parameter yang dapat untuk melakukan pengaturan calam chatbot.Pada Gambar 7 Tampilan setting intent yang digunakan pada kategori Info Magang 
Sedangkan pada Gambar 8, Admin dapat melakukan cek history conversation dalam sistem sebagai berikut:

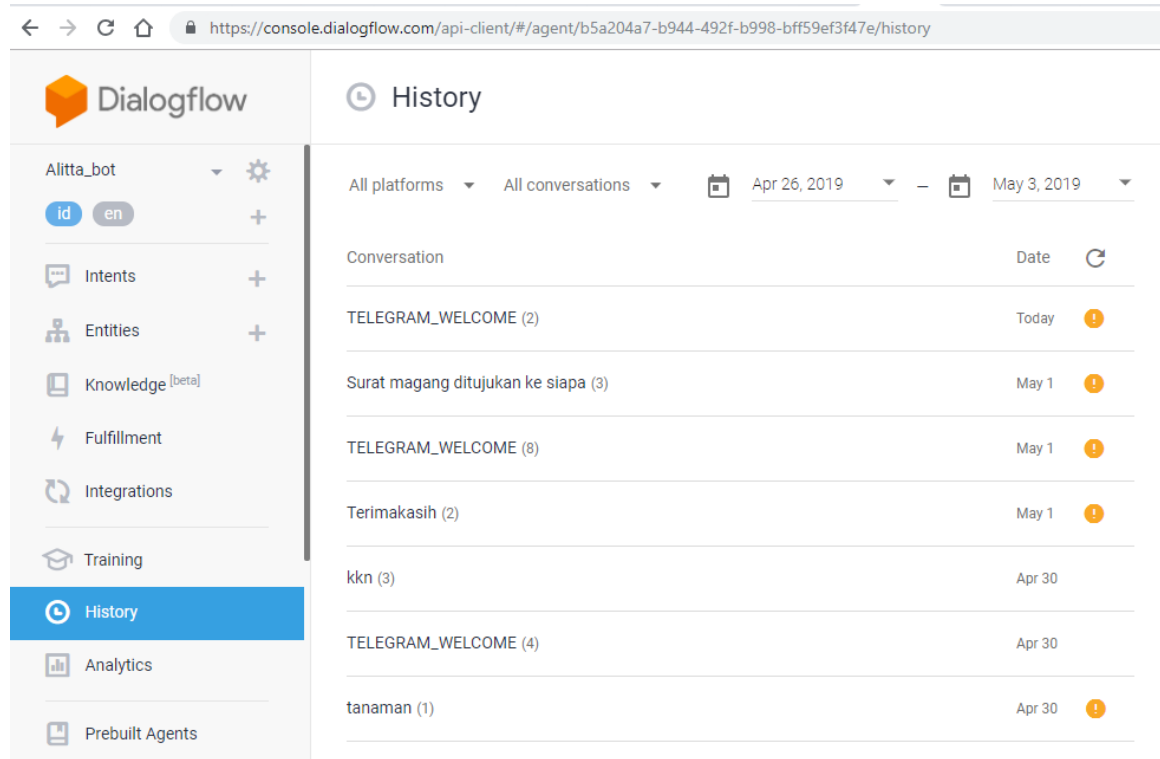

Gambar 8 Tampilan History Chat

Tampilan History Chat dapat digunakan untuk melakukan follow up terhadap keseluruhan conversation yang telah dijalankan oleh sistem chatbot ALITTA. Penggunaan Diagflow/ API.AI sebagai salah satu framework dalam pembuatan chatbot yang dapat melakukan integrasi terhadap website maupun social media.

\section{KESIMPULAN}

Dari hasil penelitian dapat diambil kesimpulan sebagai berikut :

1. Chatbot dapat digunakan untuk membantu kegiatan tanya jawab yang sering kali ditanyakan berulangulang yang dapat dilakukan setiap saat tanpa terkendala waktu.

2. Penggunaan NLP dalam chatbot memudahkan untuk user dalam memahami informasi yang dibutuhkan karena sesuai dengan bahasa alami user.

3. Chatbot sebagai salah satu inovasi teknologi dalam penunjang kegiatan yang berbasis layanan kepada pelanggan.

4. Untuk pengembangan lebih lanjut dapat dilakukan pengembangan chatbot di sosial media yang dimiliki oleh Balittas.

\section{DAFTAR PUSTAKA}

[1] http://balittas.litbang.pertanian.go.id/index.php/id/tentang-kami Dikutip pada tanggal 28 Juni 2019 Pukul 10.29 WIB.

[2] Accenture Interactive., (2016). CHATBOTS IN CUSTOMER SERVICE. Tersedia di : https://www.accenture.com/t00010101T000000_w /br-pt/_acnmedia/PDF-45/Accenture-ChatbotsCustomer-Service.pdf

[3] Sasmito Aribowo. A., Khomsah, Siti. Sistem Pakar Dengan Beberapa Knowledge Base Menggunakan Probabilitas Bayes Dan Mesin Inferensi Forward Chaining. Seminar Nasional Informatika 2011 (semnasIF 2011). Dipresentasikan di (semnasIF 2011) UPN "Veteran" Yogyakarta, 2 Juli 2011.[Online]. Tersedia : http://jurnal.upnyk.ac.id/index.php/semnasif/article/view/1267 
[4] Setiaji, Hari., Kurniawan, Rahardian. Sistem Informasi Penelitian Dan Pengabdian Dosen Guna Otomatisasi Penentuan Angka Kredit Dosen Dan Mendukung Aktivitas Tridharma Perguruan Tinggi. Seminar Nasional Aplikasi Teknologi Informasi 2011 (SNATI 2011) Universitas Islam Indonesia, Yogyakarta, 17-18 Juni 2011. [Online]. Tersedia : https://www.neliti.com/publications/88557/sisteminformasi-penelitian-dan-pengabdian-dosen-guna-otomatisasi-penentuan-angk 